\title{
Reduction and Carburization of Iron Oxides for Fischer-Tropsch Synthesis
}

\author{
Nielsen, Monia Runge; Moss, Asger Barkholt; Bjørnlund, Anton Simon; Liu, Xi; Knop-Gericke, Axel; \\ Klyushin, Alexander Yu; Grunwaldt, Jan-Dierk; Sheppard, Thomas L.; Doronkin, Dmitry E.; Zimina, Anna \\ Total number of authors: \\ 15
}

Publication date:

2020

Document Version

Publisher's PDF, also known as Version of record

Link back to DTU Orbit

Citation (APA):

Nielsen, M. R., Moss, A. B., Bjørnlund, A. S., Liu, X., Knop-Gericke, A., Klyushin, A. Y., Grunwaldt, J-D., Sheppard, T. L., Doronkin, D. E., Zimina, A., Smitshuysen, T. E. L., Fam, Y., Damsgaard, C. D., Wagner, J. B., \& Hansen, T. W. (2020). Reduction and Carburization of Iron Oxides for Fischer-Tropsch Synthesis. Abstract from Microscopy and Microanalysis 2020, Milwaukee, Wisconsin, United States.

\section{General rights}

Copyright and moral rights for the publications made accessible in the public portal are retained by the authors and/or other copyright owners and it is a condition of accessing publications that users recognise and abide by the legal requirements associated with these rights.

- Users may download and print one copy of any publication from the public portal for the purpose of private study or research.

- You may not further distribute the material or use it for any profit-making activity or commercial gain

- You may freely distribute the URL identifying the publication in the public portal 


\section{Reduction and Carburization of Iron Oxides for Fischer-Tropsch Synthesis}

Monia Runge Nielsen ${ }^{1}$, Asger Barkholt Moss ${ }^{1,2}$, Anton Simon Bjørnlund ${ }^{1,2}$, Xi Liu ${ }^{3,4}$, Axel KnopGericke $^{5,6}$, Alexander Yu. Klyushin ${ }^{5,7}$, Jan-Dierk Grunwaldt ${ }^{8,9}$, Thomas L. Sheppard ${ }^{8,9}$, Dmitry E. Doronkin $^{8,9}$, Anna Zimina ${ }^{8,9}$, Thomas Eric Lyck Smitshuysen ${ }^{2}$, Yakub Fam ${ }^{1}$, Christian Danvad Damsgaard $^{1,2}$, Jakob Birkedal Wagner ${ }^{1}$, Thomas Willum Hansen ${ }^{1}$

${ }^{1}$ DTU Nanolab, Technical University of Denmark, DK-2800 Kgs. Lyngby, Denmark

${ }^{2}$ Department of Physics, Technical University of Denmark, DK-2800 Kgs. Lyngby, Denmark

${ }^{3}$ SynCat@Beijing, Synfuels China Technology Co., Ltd, Beijing, 101407, China

${ }^{4}$ School of Chemistry and Chemical Engineering, Shanghai Jiao Tong University, 200240, Shanghai, China

${ }^{5}$ Department of Inorganic Chemistry, Fritz Haber Institute of the Max Planck Society, D-14195 Berlin, Germany

${ }^{6}$ Research Group Heterogeneous Reactions, Max Planck Institute for Chemical Energy Conversion, D45470 Mülheim, Germany

${ }^{7}$ Research Group Catalysis for Energy, Helmholtz-Zentrum Berlin for Materials and Energy (BESSY II), D-12489 Berlin, Germany

${ }^{8}$ Institute for Chemical Technology and Polymer Chemistry, Karlsruhe Institute of Technology, D76131 Karlsruhe, Germany

${ }^{9}$ Institute of Catalysis Research and Technology, Karlsruhe Institute of Technology, D-76344 Eggenstein-Leopoldshafen, Germany

Fischer-Tropsch Synthesis (FTS) is the chemical reaction in which a mixture of carbon monoxide and hydrogen (syngas) is converted into mainly hydrocarbons which are subsequently used for making liquid fuels and chemicals. Iron and cobalt are the most commonly used catalysts in industrial FTS [1]. Compared to cobalt, iron is cheaper as it is one of the most abundant elements in the crust of the earth. Iron catalysts are less active but also less impacted by operating conditions, i.e. pressure and temperature.

The activation of an iron-based FTS catalysts typically consists of two steps: reduction in hydrogen followed by carburization in either $\mathrm{CO}$ or syngas mixture. Alternatively, both steps can be carried out simultaneously in syngas. A combination of different complementary in situ techniques was used to gain insight into the behavior of Fe-based FTS catalysts during these steps. In situ XRD was used to identify the crystalline phases present during both steps. From the XRD data, an increase in reduction rate was observed with increasing temperature. In situ X-ray diffraction experiments in $\mathrm{H}_{2}$ at a flow of $2 \mathrm{Nml} / \mathrm{min}$ corresponding to a $\mathrm{H}_{2}$ partial pressure of $14 \mathrm{mbar}$ at the sample show the temperature dependence of the reduction process. Metallic iron is present already at around $400^{\circ} \mathrm{C}$ and at $700^{\circ} \mathrm{C}$ the sample is fully reduced. However, these experiments do not provide any information on how the reduction properties depends on the structure. 
To further investigate the structural effects of the reduction process, environmental transmission electron microscopy (ETEM) was used [2]. The experiments were carried out at low pressure using an aberration corrected FEI Titan 80-300 E-cell, operated at $300 \mathrm{kV}$. The sample was dispersed in ethanol and sonicated for $15 \mathrm{~min}$. prior to drop casting onto a through-hole Wildfire heating chip from DENSsolutions. Iron oxide was reduced in situ in hydrogen at temperatures up to $500^{\circ} \mathrm{C}$ at various pressures in the range 1.3-3.8 mbar. High-pressure studies were carried out using the Climate closed gas-cell holder from DENSsolutions, with a gas flow up to $0.9 \mathrm{Nml} / \mathrm{min}$ and a maximum pressure of $1 \mathrm{~atm}$. In order to minimize the effect of the electron beam, the beam was turned off while ramping the temperature between each image/diffraction/spectrum acquisition.

Both oxides and metallic iron were observed during the reduction using in situ XRD. These were further confirmed when reducing iron oxide in the ETEM. With a pressure of $1.3 \mathrm{mbar}_{2}$ at a flow of $2 \mathrm{Nml} / \mathrm{min}$, iron oxide was reduced to metallic iron at $500^{\circ} \mathrm{C}$ as confirmed by electron energy-loss spectroscopy (EELS), Figure 1. With limited beam influence, hematite was completely reduced at $500^{\circ} \mathrm{C}$. At $450^{\circ} \mathrm{C}$, imaging and diffraction indicated a clear dependence on agglomerate size, Figure 2 . At this temperature, diffraction patterns from the larger agglomerate in Figure 2a indicate the presence of both metallic iron as well as hematite while under the same conditions, the smaller agglomerate in Figure $2 \mathrm{~b}$ show only metallic iron. A possible explanation could be the presence of water produced during the reduction process.

In conclusion, in the ETEM, complete reduction to metallic was demonstrated and an effect of agglomerate size was apparent. Both ETEM and high pressure experiments indicate that smaller agglomerates reduce at lower temperatures than larger agglomerates.

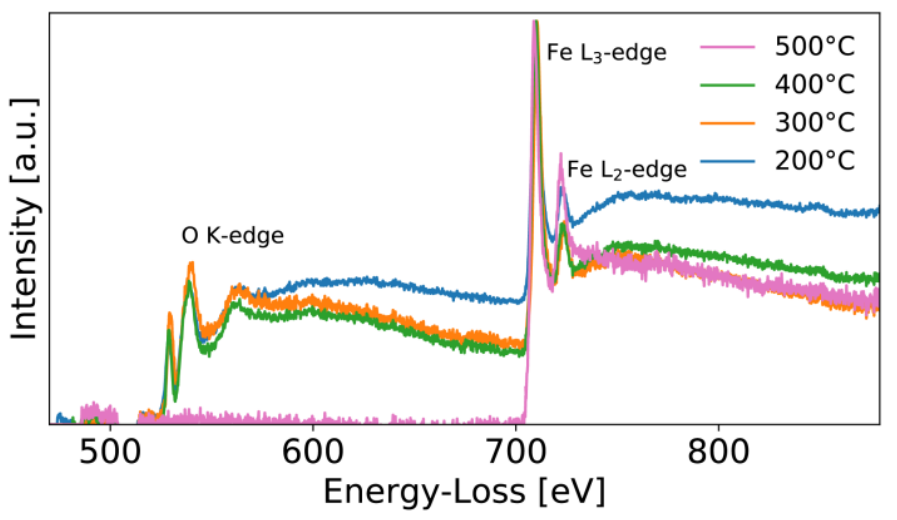

Figure 1: EELS data from the reduction of hematite at increasing temperatures, showing the oxygen K-edge ( $\sim 532 \mathrm{eV})$ and the iron L-edge ( $708 \mathrm{eV})$. The data is normalized at the peak intensity at the Fe $\mathrm{L}_{3}$-edge.
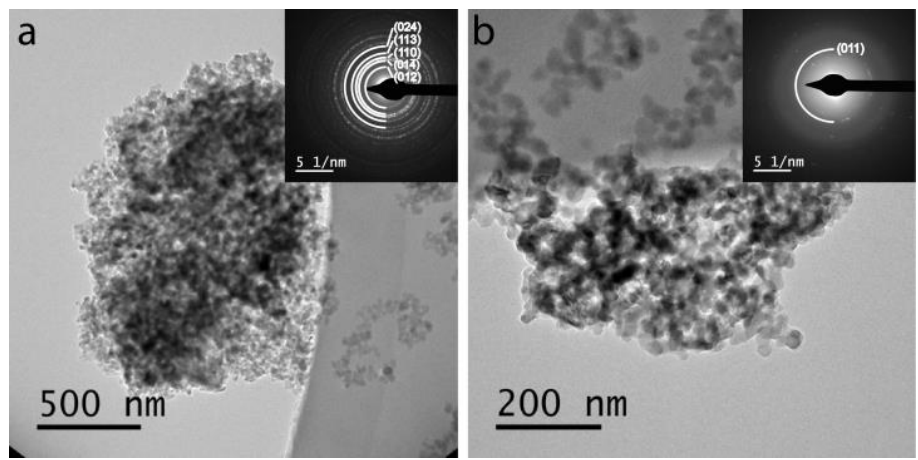

Figure 2: Two agglomerates of different size with corresponding electron diffraction patterns acquired at $450^{\circ} \mathrm{C}$, showing a) both the presence of hematite and b) metallic iron. The images and diffraction patterns were acquired under the same conditions. 
[1] B. H. Davis, Catal. Today 84, (2003) 83-98.

[2] T. W. Hansen, J. B. Wagner, R. E. Dunin-Borkowski, Mater. Sci. Technol. 26, (2010) 1338-1344. 